Acta Botanica Brasilica - 35(4): 698-702. October-December 2021.

\title{
Localised photosynthetic pigments in the node of a holoparasitic plant: support for shoot growth?
}

\section{André Geremia Parise* (D), Luis Felipe Basso ${ }^{1}$ (D) Ricardo Padilha de Oliveira ${ }^{1}$ (1) and Gabriela Niemeyer Reissig ${ }^{1}$ (C)}

Received: June 28, 2020

Accepted: December 1, 2020

\begin{abstract}
Understanding the role of photosynthesis in the holoparasitic genus Cuscuta may give insights into the biology and evolution of these plants. We hypothesised that light irradiance on the node of $C$. racemosa is important for sustaining the growth of the new shoot through photosynthesis. We blocked light irradiance on the node of detached twigs of C. racemosa for one week and measured twig fresh and dry weight, shoot length and photosynthetic pigment content. Even though fresh and dry weight did not differ between non-irradiated and irradiated twigs, the shoots of non-irradiated nodes were significantly shorter. The non-irradiated plants showed higher amounts of chlorophyll $a, b$, and lycopene, and a lower concentration of $\beta$-carotene. Furthermore, the chlorophyll $a / b$ ratio was lower than that of the control (irradiated) plants. Beyond corroborating our hypothesis, our results suggest that, when light is blocked on the node of $C$. racemosa, the holoparasite responds in a way similar to that of autotrophic plants under shaded conditions. Our findings suggest a new and previously unacknowledged role for the node of $C$. racemosa, which would be supporting shoot elongation through photosynthesis.
\end{abstract}

Keywords: $\beta$-carotene, carotenoids, chlorophyll, chlorophyll $a / b$ ratio, Cuscuta racemosa, lycopene, plant physiology, photosynthesis

\footnotetext{
1 Laboratório de Cognição e Eletrofisiologia Vegetal, Departamento de Botânica, Instituto de Biologia, Universidade Federal de Pelotas, 96160-000, Capão do Leão, RS, Brazil

*Corresponding author: andregparise@gmail.com
} 


\section{Introduction}

Dodders (Convolvulaceae: Cuscuta spp.) are holoparasitic plants which occur in all the continents, except Antarctica (Costea \& Stefanović 2010). Typically, they resemble a mass of yellow or orange stems with, at most, minute vestigial scale-like leaves, growing on their plant hosts (Hibberd et al. 1998). They do not have roots, and they absorb all their nutrients through haustoria, which are connected to the hosts (Birschwilks et al. 2006; Costea \& Tardif 2006). Dodders are some of the most devastating agricultural parasites worldwide; however, they are also ecologically relevant owing to the strong effect of their parasitism on the fitness of wild plants and invasive species (Costea \& Tardif 2006; Albert et al. 2008; Mishra 2009; Cruz Neto et al. 2017; Wu et al. 2019).

Some dodder species exhibit extremely limited photosynthetic ability, and they cannot live autotrophically (Machado \& Zetsche 1990; Hibberd et al. 1998). However, under certain conditions, they can synthesise high amounts of chlorophylls (Walzel 1952; Laudi 1968). Indeed, these species harbour many functional photosynthetic plastidial genes and exhibit Rubisco activity, functional electron transport in the photosystems, and $\mathrm{CO}_{2}$ fixation (MacLeod 1961; Ciferri \& Poma 1962; 1963; Pattee et al. 1965; Baccarini 1966; Machado \& Zetsche 1990; Hibberd et al. 1998; McNeal et al. 2007). This limited photosynthetic activity is likely triggered during the pre-attachment stage of the seedlings or when the plant is malnourished, such as when detached from its host or growing on a low-quality host (Peirce 1894; Pizzolongo 1963; Pattee et al. 1965; Laudi 1968; Lyshede 1985). In a previous study (Parise et al. 2021), we observed that a twig of Cuscuta racemosa Mart. detached from the original plant (and from its host) accumulated chlorophyll, particularly in the nodal region (Fig. 1), and the node became greener than the rest of the stem within a few days.

To the best of our knowledge, however, there has been no previous report of chlorophyll accumulation in $C$. racemosa, and the physiology of this plant remains largely unknown. The high photosynthetic pigment content in the node may be important for sustaining the growth of the new shoot while searching for a suitable host. Moreover, by enriching this metabolically active region with pigments, photosynthesis and other photochemical activities may be facilitated at the regions from which the new shoot sprouts. Shoot growth would directly benefit from the products of these photochemical activities through either the Calvin cycle or other. McNeal et al. (2007) suggested that dodders could possess an alternative pathway for lipid synthesis which requires a non-photosynthetic activity of Rubisco and could justify the seemingly obsolete photosynthetic apparatus in the genus. This pathway is more efficient in carbon use than the glycolytic pathway, and its efficiency improves with increasing light irradiance. Nevertheless, the photochemical phase of photosynthesis is needed to supply this pathway with ATP and NADPH (Schwender et al. 2004).

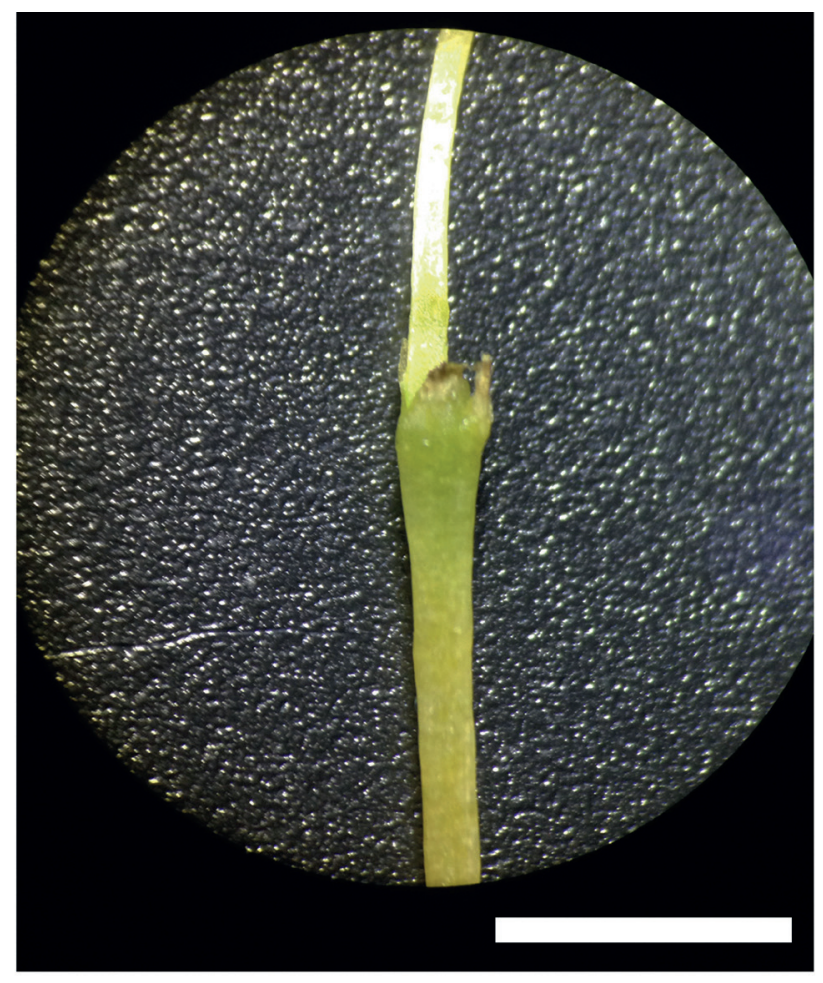

Figure 1. Node of a detached Cuscuta racemosa enriched with green pigments. The white bar represents $0.5 \mathrm{~cm}$. The whole figure had its colour balance adjusted for evidencing colder shades.

Regardless of the mechanisms through which C. racemosa accumulates pigments at the node, light and photosynthetic pigments seem highly physiologically relevant. Thus, we hypothesised that blocking light irradiance to the node would impair bud development, because the plant would not be able to harvest light properly. Additionally, since plants in low-light environments present high chlorophylls content to augment photosynthetic efficiency (Lüttge 2008; Souza et al. 2009; Ferreira et al. 2012), we hypothesised that blocking light irradiance to the node would increase the chlorophyll $a$ and chlorophyll $b$ content in the plants. Meanwhile, since dodders generally present a high carotenoid content (Baccarini et al. 1965; Dinelli et al. 1993; Villa-Ruano et al. 2017), we expected no significant change in the content of lycopene and $\beta$-carotene, which are important carotenoids for plants, because of the blocking of light irradiance to the node.

\section{Materials and methods}

The present study was conducted at the campus of Capão do Leão of the Federal University of Pelotas (31 $48^{\prime} 06^{\prime \prime}$, $52^{\circ} 25^{\prime} 02^{\prime \prime} \mathrm{W}$ ), Rio Grande do Sul, Brazil. During the spring of 2019, a twig of Cuscuta racemosa Mart. was collected from 
an ornamental plant in central Pelotas, Rio Grande do Sul, Brazil, and cultivated on basil plants (Ocimum sp.) at the campus in a greenhouse at $28.5 \pm 12.9{ }^{\circ} \mathrm{C}$ under natural sunlight. When the dodders grew large enough to cover all the hosts, they were used as the stock of $C$. racemosa in the present experiment. The host plants were irrigated twice a week with approximately $200 \mathrm{~mL}$ of Hoagland and Arnon solution (Hoagland \& Arnon 1950). After allowing to grow for 3 months, the dodders were used in the experiment. Twigs were collected from the stock and trimmed to a length of $10 \mathrm{~cm}$, with only one node at the apical end. All shoots sprouting from the node were excised, leaving only a single bud. All twigs weighed approximately $0.118 \pm 0.006 \mathrm{~g}$.

We used six polystyrene boxes (dimensions $20.0 \times 25.0$ $\times 17.0 \mathrm{~cm}$ ), three of each for the experimental and control treatments. A polystyrene shelf $(12.0 \times 17.0 \mathrm{~cm})$ was installed at a depth of $5.0 \mathrm{~cm}$ in each box, and four twigs were placed on the shelves parallel to one another and to the longer side of the box. This arrangement ensured homogenous light irradiance to all twigs. The boxes were then covered with transparent plastic films to maintain humidity.

In the experimental group, light to the node was blocked by wrapping it with a $0.3-\mathrm{cm}$-wide strip of aluminium foil. In the control group, a similar aluminium foil strip was used to wrap the stem immediately below the node to maintain the effect of the aluminium foil while allowing the node to be illuminated. The boxes containing the twigs were incubated in the growing room of the Laboratório de Cognição e Eletrofisiologia Vegetal (LACEV) at the Universidade Federal de Pelotas at a constant temperature of $25.0 \pm 2{ }^{\circ} \mathrm{C}$ under a photoperiod of $12.0 \mathrm{~h}$. The plants were placed $50.0 \mathrm{~cm}$ below the row of four LED lightbulbs of $50.0 \mathrm{~W}$ and approximately 5,000 lumens, with each emitting white light. After 1 week, the dodders were removed from the boxes and analysed.

The initial fresh weight was measured before the treatment, and the final fresh weight and the length of the new shoot were measured after the treatment. From each box, two dodder twigs were randomly selected for biochemical analyses and two for measuring the dry weight.

The content of chlorophyll $a$, chlorophyll $b$, lycopene, and $\beta$-carotene were measured using spectrophotometry according to the protocol described by Nagata and Yamashita (1992) with slight modification. Briefly, whole twigs were macerated in hexane:acetone (2:3) and vortexed for $30.0 \mathrm{~s}$. Absorbance of the supernatant was measured using a spectrophotometer (Utrospec 7000, Biochrom', Cambridge, $\mathrm{UK})$. The results were expressed in $\mathrm{mg} 100 \mathrm{~g}^{-1}$ of fresh weight. With the content of chlorophyll $a$ and $b$, we calculated the chlorophyll $a / b$ ratio. To determine dry weight, the twigs were placed in a dryer at $44.0 \pm 1^{\circ} \mathrm{C}$ for 1 week and weighed using a semi-analytical balance (Marte ${ }^{\circ}$, model BL-320H, Santa Rita do Sapucaí, MG, Brazil).

Each treatment was performed with three replicates, totalling 12 observations per treatment (four twigs per box). The experimental design was completely randomised, and the data were analysed using ANOVA. When the F-values were significant, the treatments were compared using Student's $t$-test $(\mathrm{p} \leq 0.05)$.

\section{Results}

The results of shoot growth and fresh and dry weight are shown in Table 1 . The results for biochemical analyses are shown in Table 2 . There was a significant difference $(\mathrm{p} \leq$ 0.05 ) in shoot length between the two groups, with longer shoots in the control group. Chlorophyll $a$, chlorophyll $b$, and lycopene content was higher in the treatment group, whereas $\beta$-carotene content was higher in the control group.

Table 1. Fresh initial weight (FIW), fresh final weight (FFW), dry weight (DW) and shoot length (SL) of dodder twigs with and without aluminium foil involving the node. Values represent the mean + SD $(n=12)$. Means followed by * showed significant difference $(\mathrm{p} \leq 0.05)$ by Student's $t$-test.

\begin{tabular}{|c|c|c|}
\hline & Control & Test \\
\hline FIW $(\mathrm{g})$ & $0.113 \pm 0.004$ & $0.116 \pm 0.006$ \\
\hline FFW $(\mathrm{g})$ & $0.078 \pm 0.009$ & $0.078 \pm 0.011$ \\
\hline DW $(\mathrm{g})$ & $0.008 \pm 0.001$ & $0.007 \pm 0.001$ \\
\hline SL $(\mathrm{cm})$ & $12.952 \pm 0.447^{*}$ & $11.559 \pm 0.482$ \\
\hline
\end{tabular}

Table 2. Content of chlorophyll $a$, chlorophyll $b$, lycopene and $\beta$-carotene in the dodders with and without aluminium foil involving the node. Values represent mean $+S D(n=12)$. Means followed by ${ }^{*}$ showed significant difference difference $(\mathrm{p} \leq 0.05)$ by Student's $t$-test. Values expressed in $\mathrm{mg} 100 \mathrm{~g}^{-1}$ of fresh weight.

\begin{tabular}{|c|c|c|}
\hline & Control & Test \\
\hline Chlorophyll $a$ & $4.030 \pm 0.562$ & $5.635 \pm 0.483^{*}$ \\
\hline Chlorophyll $b$ & $2.436 \pm 0.198$ & $4.092 \pm 0.615^{*}$ \\
\hline Lycopene & $0.791 \pm 0.067$ & $1.107 \pm 0.130^{*}$ \\
\hline$\beta$-carotene & $7.813 \pm 0.402^{*}$ & $7.112 \pm 0.136$ \\
\hline
\end{tabular}

\section{Discussion}

Our results showed that the shoot length of $C$. racemosa was significantly shortened when light irradiance to the node was blocked, suggesting that light, specifically at this region, is important for shoot growth. Other growth parameters, however, did not show a significant difference, which indicates the possibility that this result was due to some impairment on elongation mechanisms such as, e.g., the acid growth of the cells. Moreover, the higher chlorophyll content observed in the experimental group corroborated our hypothesis that blocking light irradiance to the node would increase chlorophyll content. However, the increase in lycopene content in the experimental group was unexpected.

Notably, the chlorophyll $a / b$ ratio was different between the experimental and control groups (1.4 and 1.7, respectively). Blocking of light irradiance to the node increased chlorophyll $b$ content by $68 \%$ compared with 
the control value. Thus, despite the increase in chlorophyll $a$ content, the chlorophyll $a / b$ ratio was lower in the experimental group than in the control group. Such increases in total chlorophyll content and chlorophyll $a / b$ ratio are important for plant acclimation to low-light environments and have been observed in many autotrophic taxa (Lüttge 2008; Souza et al. 2009; Ferreira et al. 2012; Agathokleous et al. 2020). Chlorophyll $a$ and $b$ absorb light energy at different wavelengths, thus improving the capture of photons required for the photochemical steps of photosynthesis. With slightly different absorption properties, both chlorophyll $a$ and $b$ enhance the performance of the antenna complexes. For this, the specific binding sites of these complexes must be occupied by either chlorophyll $a$ or chlorophyll $b$ (Souza et al. 2009; Palm et al. 2018). Therefore, we suggest that, in the experimental group, the twigs of $C$. racemosa were enhancing its light-harvesting efficiency in the node by synthesising more photosynthetic pigments to increase the chances of catching photons in the node, probably, to maximise the photon capture at the nodes and compensate for the lack of illumination on this part of the plant. Of note, based on the analysed parameters, $C$. racemosa responded to low-light conditions in the same manner as photoautotrophic plants.

Given this result, at first glance, it could be hypothesised that the dodder, by refraining its growth, would be avoiding the shade cast by the aluminium foil. However, the literature available suggests that dodders present the opposite behaviour and have positive tropism towards sources of shade - when it is enriched with far-red radiation - which is indicative of photosynthetic plants nearby (Orr et al. 1996; Benvenuti et al. 2005). Additionally, only the node was covered in the experimental group and an equal portion of the internode was covered in the control group. Therefore, plants in both groups received the same amount of light. In conclusion, it is unlikely that the observed behaviour was caused due to shade avoidance.

A higher $\beta$-carotene content was observed in the control group than in the experimental group, supporting the photoprotective function of carotenoids in vascular plants (Sun et al. 2018). $\beta$-Carotene and several xanthophylls (e.g. lutein, zeaxanthin, and violaxanthin) are the constituents of functional multiprotein complexes, such as photosystems I and

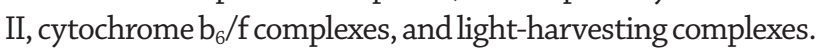
The protein components of these structures are surrounded and/or bound together by carotenoids through hydrophobic interactions (Domonkos et al. 2013). They also participate in the xanthophyll cycle, which is associated with non-photochemical quenching - an energy dissipation mechanism.

Nonetheless, the observed increase in $\beta$-carotene content may not necessarily be related to the photoprotection of the photosynthetic apparatus alone, as carotenoids play many other roles in plants such as free radical scavenging, phytohormone synthesis (e.g., ABA), flower and fruit colouration, and membrane protection from lipid peroxidation in the entire cell and not just in the chloroplast (Zakynthinos \& Varzakas 2016; Rodriguez-Concepcion et al. 2018).

In plant cells, carotenoids are biosynthesised and stored in the plastids, with chloroplasts and chromoplasts showing a higher carotenoid content than other plastids (Sun et al. 2018). In a previous carotenoid profiling study, Villa-Ruano et al. (2017) reported higher $\beta$-carotene and lycopene content in C. mitraeformis Engelm. ex Hemsl. than the content noted in the present study in C. racemosa. The higher $\beta$-carotene content in C. mitraeformis (77.4 \pm $5.7 \mathrm{mg}$ per $100 \mathrm{~g}$ of fresh weight) may be explained by the differences in species, environmental conditions, and carotenoid extraction protocols.

Conversely, blocking of light irradiance at the node increased the lycopene content of dodders. Lycopene is an intermediate of $\beta$-carotene in its biosynthesis, and its increase may be related to the decrease of $\beta$-carotene. The absence of light at the node of $C$. racemosa might have affected the expression of enzymatic genes or the activity of enzymes involved in various biosynthetic steps, thereby decreasing $\beta$-carotene content and leading to lycopene accumulation.

Carotenoid biosynthesis begins with the formation of isopentenyl diphosphate and dimethylallyl diphosphate via the methylerythritol 4-phosphate pathway. In the next step, phytoene synthase catalyses the condensation of two geranylgeranyl diphosphate molecules into phytoene. Finally, lycopene cyclisation yields the a-carotene and $\beta$-carotene branches of the pathway, the latter being catalysed by lycopene $\beta$-cyclase.

In conclusion, under limited resources due to the unavailability of a host, C. racemosa increased photosynthetic pigment content, presumably at the expense of shoot growth, which might explain the smaller shoots in the experimental group than in the control group of this study. Further studies will be needed to verify where the dodders synthesised the higher amounts of chlorophylls. Was it in the illuminated parts of the shoot to compensate for the lack of light at the node, or just in the node to enhance light harvest there? It will increase the knowledge on the importance of nodes and photosynthesis to the shoot growth of $C$. racemosa. Our results raise questions regarding the precise role of photosynthesis and photosynthetic pigments in this holoparasitic plant as well as the importance of nodes in this process.

\section{Acknowledgements}

We thank Dr Eugenia Jacira Bolacel Braga and Dr Flávia Maria da Silva Carmo (in memoriam) for reviewing the earlier form of this manuscript, Dr Willian Silva Barros for the help with the statistics, and Dr Gustavo Maia Souza for the overall support. This study was financed in part by the Coordenação de Aperfeiçoamento de Pessoal de Nível Superior - Brasil (CAPES) - Finance Code 001. AGP was granted with a scholarship from the CAPES. 


\section{References}

Agathokleous E, Feng Z, Peñuelas J. 2020. Chlorophyll hormesis: are chlorophylls major components of stress biology in higher plants? Science of The Total Environment 726: 138637. doi: 10.1016/j. scitotenv.2020.138637

Albert M, Belastegui-Macadam X, Bleischwitz M, Kaldenhoff R. 2008. Cuscuta spp: "Parasitic plants in the spotlight of plant physiology, economy and ecology". In: Lüttge U, Beyschlag W, Murata J. (eds.) Progress in Botany 69. Germany, Springer-Verlag Berlin Heidelberg. p. 267-277.

Baccarini A, Bertossi F, Bagni N. 1965. Carotenoid pigments in the stem of Cuscuta autralis. Phytochemistry 4: 349-351.

Baccarini A. 1966. Autotrophic incorporation of $\mathrm{C}_{14} \mathrm{O}_{2}$ in Cuscuta australis in relation to its parasitism. Experientia 22: 46-47.

Benvenuti S, Dinelli G, Bonetti A, Catizone P. 2005. Germination ecology, emergence and host detection in Cuscuta campestris. Weed Research 45: 270-278.

Birschwilks M, Haupt S, Hofius D, Neumann S. 2006. Transfer of phloemmobile substances from the host plants to the holoparasite Cuscuta sp. Journal of Experimental Botany 57: 911-921.

Ciferri O, Poma G. 1962. Fissazione di $\mathrm{CO}_{2}$ in Cuscuta epithymum. Giornale Botanico Italiano 69: 289-290.

Ciferri O, Poma G. 1963. Fissazione dell'anidride carbonica da parte di «Cuscuta epithymum». Giornale Botanico Italiano 70: 345-346.

Costea M, Stefanović S. 2010. Evolutionary history and taxonomy of Cuscuta umbellata complex (Convolvulaceae): Evidence of extensive hybridization from discordant nuclear and plastid phylogenies. Taxon 59: 1783-1800.

Costea M, Tardif FJ. 2006. The biology of Canadian weeds. 133. Cuscuta campestris Yuncker, C. gronovii Willd. ex Schult., C. umbrosa Beyr. ex Hook., C. epithymum (L.) L. and C. epilinum Weihe. Canadian Journal of Plant Science 86: 293-316.

Cruz Neto O, Leal IR, Santos JC, Lopes AV. 2017. A holoparasitic plant severely reduces the vegetative and reproductive performance of its host plant in the Caatinga, a Brazilian seasonally dry forest. Acta Botanica Brasilica 31: 147-152.

Dinelli G, Bonetti A, Tibiletti E. 1993. Photosynthetic and accessory pigments in Cuscuta campestris Yuncker and some host species. Weed Research 33: 253-260.

Domonkos I, Kis M, Gombos Z, Ughy B. 2013. Carotenoids, versatile components of oxygenic photosynthesis. Progress in Lipid Research 52: 539-561.

Ferreira WN, Zandavalli RB, Bezerra AME, Medeiros Filho S. 2012. Crescimento inicial de Piptadenia stipulacea (Benth.) Ducke (Mimosaceae) e Anadenanthera colubrina (Vell.) Brenan var. cebil (Griseb.) Altshul (Mimosaceae) sob diferentes níveis de sombreamento. Acta Botanica Brasilica 26: 408-414.

Hibberd JM, Bungard RA, Press MC, Jeschke WD, Scholes JD, Quick WP. 1998. Localization of photosynthetic metabolism in the parasitic angiosperm Cuscuta reflexa. Planta 205: 506-513.

Hoagland DR, Arnon DI. 1950. The water-culture method for growing plants without soil. California Agricultural Experiment Station Circular 347. California, USA, CAB Direct. https://www.cabdirect.org/cabdirect/ abstract/19500302257. 08 Oct. 2021.
Laudi G. 1968. Ultrastructural researches on the plastids of parasitic plants. IV. Galls of Cuscuta australis. Giornale Botanico Italiano 102: 37-41.

Lüttge U. 2008. Physiological ecology of tropical plants. 2nd. edn. Germany, Springer-Verlag Berlin Heidelberg.

Lyshede OB. 1985. Morphological and anatomical features of Cuscuta pedicellata and C. campestris. Nordic Journal of Botany 5: 65-77.

Machado AMA, Zetsche K. 1990. A structural, functional and molecular analysis of plastids of the holoparasites Cuscuta reflexa and Cuscuta europaea. Planta 181: 91-96.

MacLeod D. 1961. Photosynthesis in Cuscuta. Experientia 17: 542-543.

McNeal JR, Kuehl J V, Boore JL, De Pamphilis CW. 2007. Complete plastid genome sequences suggest strong selection for retention of photosynthetic genes in the parasitic plant genus. BMC Plant Biology 7: 1-22.

Mishra J. 2009. Biology and management of Cuscuta species. Indian Journal of Weed Science 41: 1-11.

Nagata M, Yamashita I. 1992. Simple method for simultaneous determination of chlorophyll and carotenoids in tomato fruit. Nippon Shokuhin Kogyo Gakkaishi 39: 925-928.

Orr GL, Haidar MA, Orr DA. 1996. Smallseed Dodder (Cuscuta planifolia) phototropism toward far-red when in white light. Weed Science 44: 233-240.

Palm DM, Agostini A, Averesch V, et al. 2018. Chlorophyll a/b binding-specificity in water-soluble chlorophyll protein. Nature Plants 4: 920-929.

Parise AG, Reissig GN, Basso LF, et al. 2021. Detection of different hosts from a distance alters the behaviour and bioelectrical activity of Cuscuta racemosa. Frontiers in Plant Science 12: 594195. doi: 10.3389/fpls.2021.594195

Pattee HE, Allred KR, Wiebe HH. 1965. Photosynthesis in Dodder. Weeds 13: 193-195.

Peirce GJ. 1894. A contribution to the physiology of the genus Cuscuta. Annals of Botany 8: 53-118.

Pizzolongo P. 1963. Sui pigmenti di Cuscuta pentagona Engel. Delpinoa 5: 9-16.

Rodriguez-Concepcion M, Avalos J, Bonet ML, et al. 2018. A global perspective on carotenoids: metabolism, biotechnology, and benefits for nutrition and health. Progress in Lipid Research 70: 62-93.

Schwender J, Goffman F, Ohlrogge JB, Shachar-Hill Y. 2004. Rubisco without the Calvin cycle improves the carbon efficiency of developing green seeds. Nature 432: 779-782.

Souza GM, Balmant BD, Vítolo HF, et al. 2009. Estratégias de utilização de luz e estabilidade do desenvolvimento de plântulas de Cordia superba Cham. (Boraginaceae) crescidas em diferentes ambientes luminosos. Acta Botanica Brasilica 23: 474-485.

Sun T, Yuan H, Cao H, Yazdani M, Tadmor Y, Li L. 2018. Carotenoid metabolism in plants: the role of plastids. Molecular Plant 11: 58-74.

Villa-Ruano N, Pacheco-Hernández Y, Rubio-Rosas E, Cruz-Durán R, LozoyaGloria E. 2017. Essential oil composition, carotenoid profile, antioxidant and antimicrobial activities of the parasitic plant Cuscuta mitraeformis. Boletín Latinoamericano y del Caribe de Plantas Medicinales y Aromáticas 16: 463-470.

Walzel G. 1952. Vitamin C in Cuscuta. Protoplasma 41: 260-262.

Wu A-I, Zhong W, Yuan J-R, et al. 2019. The factors affecting a native obligate parasite, Cuscuta australis, in selecting an exotic weed, Humulus scandens, as its host. Scientific Reports 9: 1-8.

Zakynthinos G, Varzakas T. 2016. Carotenoids: from plants to food industry. Current Research in Nutrition and Food Science 4: 38-51. 